\title{
Pengaruh Variasi Dosis Kapur Terhadap Penurunan Kadar COD dan Fosfat Pada Limbah Usaha Laundry
}

\author{
Siti Prihatin ${ }^{a, *}$, Agung Sugiharto ${ }^{\mathrm{b}}$ \\ a Program Studi Teknik Kimia, Fakultas Teknik, Universitas Muhammadiyah Surakarta \\ * corresponding author : d500170027@student.ums.ac.id \\ DOI : $10.20885 /$ ijca.vol4 iss 2 .art2
}

\section{ARTIKEL INFO}

Diterima : 18 Juli 2021

Direvisi. : 24 Agustus 2021

Diterbitkan: 18 September 2021

Kata kunci : COD, Fosfat, Kapur,

Koagulasi, Limbah laundry

\begin{abstract}
ABSTRAK
Usaha laundry merupakan usaha yang banyak ditemukan di Indonesia, usaha ini memiliki dampak negatif bagi lingkungan. Dampak negatif dari usaha laundry berupa limbah buangan deterjen yang dapat menyebabkan pencemaran lingkungan. Pencemaran lingkungan yang disebabkan oleh limbah usaha laundry yang mengandung COD (Chemical Oxygen Demand) dan fosfat yang tinggi melebihi baku mutu yang telah ditetapkan sehingga akan menyebabkan kerusakan pada ekosistem air. Penelitian ini bertujuan untuk mengetahui pengaruh koagulan kapur yang paling efektif dengan dosis 1,8 g, 2,2 g, 2,8 g, 3,2 g, dan 3,5 g waktu pengadukan 20 menit menggunakan metode koagulasi dalam menurunkan parameter COD dan fosfat pada limbah laundry sehingga memenuhi baku mutu yang telah ditetapkan. Hasil penelitian ini menyimpulkan bahwa penurunan kadar COD yang efektif pada air limbah laundry terdapat pada penambahan dosis 3,5 gram koagulan kapur dengan presentase penurunan sebesar $88,89 \%$ dan untuk penurunan kadar fosfat yang efektif pada air limbah laundry terdapat pada penambahan dosis 1,8 gram koagulan kapur dengan presentase penurunan 99,66\% karena pada dosis tersebut sudah mampu menurunkan kadar COD dan fosfat sesuai syarat baku mutu Perda Prov. Jateng No. 5 Tahun 2012 tentang baku mutu limbah industri deterjen.
\end{abstract}

\section{ARTICLE INFO}

Received : 18 July 2021

Revised : 24 August 2021

Published: 18 September 2021

Keywords: COD, Phosphate, Lime,

Coagulation, Laundry waste

\section{ABSTRACT}

Laundry is a business that is widely found in Indonesia, this business has a negative impact on the environment. The negative impact of the laundry business is in the form of detergent waste which can cause environmental pollution. Environmental pollution caused by laundry business waste which contains COD (Chemical Oxygen Demand) and high phosphate exceeds the quality standard that has been set so that it will cause damage to the water ecosystem. The study's purposes was to determine the effect of the most effective lime coagulant with doses of $1.8 \mathrm{~g}, 2.2 \mathrm{~g}, 2.8 \mathrm{~g}, 3.2 \mathrm{~g}$, $3.5 \mathrm{~g}$ and a stirring time of 20 minutes using the coagulation method in reducing $C O D$ and phosphate parameters in laundry waste so that it meets the quality standards that have been set. The results of this study concluded that the effective decrease in COD levels in 
laundry wastewater was found in the addition of a dose of 3.5 grams of lime coagulant with a percentage decrease of $88.89 \%$ and for an effective decrease in phosphate levels in laundry wastewater there was an additional dose of 1.8 gram of lime coagulant with a percentage decrease of $99.66 \%$ because at that dose it was able to reduce the levels of COD and phosphate in accordance with the quality standard of Perda Prov. Jateng No. 5 Tahun 2012 concerning the quality standard of detergent industrial waste.

\section{PENDAHULUAN}

Salah satu penyebab dari penurunan kualitas lingkungan hidup adalah pencemaran air. Pertumbuhan penduduk menyebabkan peningkatan pencemaran pada suatu lingkungan. Pencemaran ini bisa berasal dari limbah domestik yang dihasilkan dari kegiatan sehari-hari seperti mandi, mencuci, dan memasak. Umumnya di dalam deterjen mengandung bahan seperti surfaktan yang berfungsi sebagai bahan aktif untuk menghilangkan noda atau kotoran. Surfaktan dapat berupa anionik (Alpha Olein Sulfonate/AOS, Linier Alkyl Benzene Sulfonate/LAS, atau Alkyl Benzene/ABS,), kationik (Garam Ammonium), dan non ionik (Nonyl phenol polyethoxyle). Sedangkan surfaktan yang memiliki sifat beracun bagi tubuh dan lingkungan adalah surfaktan kationik [1].

Rata-rata jumLah air yang digunakan pada industry laundry sebanyak $15 \mathrm{~L}$ untuk mencuci $1 \mathrm{~kg}$ pakaian serta limbah yang dihasilkan sebesar $400 \mathrm{~m}^{3}$ per hari. Pembuangan limbah laundry masih menjadi masalah karena bahan yang terdapat pada deterjen. Limbah ini berpotensi menimbulkan pencemaran lingkungan karena konsentrasi COD, padatan tersuspensi, padatan terlarut dan kandungan fosfat yang sukar terurai [2].Peningkatan konsentrasi COD dan kekeruhan pada badan air disebabkan oleh tingginya kandungan fosfat yang berasal dari deterjen. Air yang mengandung fosfat berlebih akan mengakibatkan lebih banyak nutrien yang terlarut pada air sehingga akan menurunkan kadar $\mathrm{O}_{2}$ terlarut dan mengurangi kemampuan badan air dalam mendukung organisme lain di air yang dikenal dengan eutrofikasi [3].

Angka COD merupakan parameter yang digunakan untuk mendeteksi pencemaran air yang disebabkan oleh zat organik. Semakin tinggi indeks COD akan mengakibatkan semakin tingginya konsentrasi $\mathrm{O}_{2}$ terlarut, semakin sedikit $\mathrm{O}_{2}$ di dalam air, dan semakin mengganggu kehidupan ekosistem perairan [4]. Parameter air limbah yang terdapat dalam limbah deterjen telah ditetapkan berdasarkan berdasarkan Perda Prov. Jateng No. 5 Tahun 2012 tentang baku mutu limbah industri deterjen sebagai berikut Tabel 1 .

TABEL I. Baku Mutu Limbah Industri Deterjen Berdasarkan Perda Prov. Jateng No. 5 Tahun 2012

\begin{tabular}{lcc}
\hline \multicolumn{1}{c}{ Parameter } & $\begin{array}{c}\text { Kadar Maksimum } \\
(\mathrm{mg} / \mathrm{L})\end{array}$ & $\begin{array}{c}\text { Beban Pencemaran } \\
\text { Maksimal }(\mathrm{kg} / \mathrm{ton} \\
\text { Produk })\end{array}$ \\
\hline COD & 180 & 0,180 \\
Fosfat $\left(\mathrm{PO}_{4}\right)$ & 2 & 0,002 \\
Minyak dan Lemak & 15 & 0,015 \\
$\mathrm{pH}$ & $6-9$ & \\
\hline
\end{tabular}

Sumber : Peraturan Menteri Lingkungan Hidup RI No. 5 Tahun 2012

Pada penelitian ini digunakan metode koagulasi karena dinilai sangat ekonomis dan aman. Koagulasi berlangsung dalam waktu singkat dengan agitasi cepat, dan koagulan yang ditambahkan untuk menghilangkan partikel non-endapan (koloid). Akibatnya, partikel koloid menggumpal dan sebagian besar dipisahkan oleh sedimentasi. [5].

Ada beberapa jenis koagulan yang dapat dimanfaatkan untuk pengolahan limbah salah satunya adalah kapur yang dapat dimanfaatkan untuk menurunkan kadar fosfat dan COD sehingga lebih ramah lingkungan saat limbah dilepas ke lingkungan. Penggunaan koagulan kapur dinilai ekonomis, nyaman dan aman digunakan untuk menurunkan konsentrasi fosfat dan COD [6]. Penelitian ini 
bertujuan untuk mencari tahu mengenai dosis koagulan kapur yang efektif dalam menurunkan kadar COD (Chemical Oxygen Demand) serta fosfat pada air limbah laundry supaya memenuhi baku mutu air limbah.

\section{METODE}

Penelitian ini bersifat eksperimental, yang menggunakan variabel bebas terdiri atas dosis koagulan kapur (1,8 g, 2,2 g, 2,8 g, 3,2 g, dan 3,5 g) dan variabel terikat terdiri atas kandungan COD dan fosfat yang terdapat pada limbah laundry. Pelaksanaan penelitian ini dilakukan di Universitas Muhammadiyah Surakarta, tepatnya di Laboratorium Teknik Kimia.

\subsection{Alat}

Pada pelaksanaannya penelitian ini memakai beberapa alat yaitu buret, corong kaca, erlenmeyer, gelas beker, hot plate, kertas saring, labu ukur, neraca analitik, peralatan jar test, $\mathrm{pH}$ meter, pipet tetes, pipet volume, rangkaian alat pengadukan, spektrofotometer, stopwatch, termometer.

\subsection{Bahan}

Pada pelaksanaannya penelitian ini memakai beberapa bahan yaitu Aquades, Asam Oksalat, $\mathrm{H}_{2} \mathrm{SO}_{4}$, Indikator phenolphthalein, Kapur, $\mathrm{KH}_{2} \mathrm{PO}_{4}, \mathrm{KMnO}_{4}$, larutan kalium antimonil tartrat, larutan ammonium molibdat, larutan asam askorbat dan sampel limbah cair laundry

\subsection{Prosedur Kerja}

\subsubsection{Pengambilan Sampel}

Penelitian ini menggunakan sampel yang didapat dari Usaha Laundry "Laundry 17" yang berlokasi di Jl. Tanuragan Raya, Nilasari, Kartasura. Sampel diambil pada pagi hari dengan menggunakan botol jerigen bersih.

\subsubsection{Proses Koagulasi}

Sampel limbah laundry diambil sebanyak $500 \mathrm{~mL}$ kemudian dimasukkan ke dalam gelas beker dan ditambahkan koagulan kapur dengan variasi massa 1,8 g, 2,2 g, 2,8 g, 3,2 g, dan 3,5 g melalui pemakaian proses Jar-Test terhadap setiap sampel. Kemudian dilakukan pengadukan dengan kecepatan $150 \mathrm{rpm}$ dengan waktu 20 menit.

\subsubsection{Proses Penentuan Kadar COD}

Standarisasi larutan $\mathrm{KMnO}_{4}$. Larutan asam oksalat $0,01 \mathrm{~N}$ sebanyak $10 \mathrm{~mL}$ dimasukkan ke dalam erlenmeyer dan menambahkan larutan $\mathrm{H}_{2} \mathrm{SO}_{4} 4 \mathrm{~N}$ sebanyak $5 \mathrm{~mL}$. Kemudian memanaskannya pada hot plate hingga suhu $\pm 80^{\circ} \mathrm{C}$ lalu mentitrasi larutan tersebut dengan larutan $\mathrm{KMnO}_{4}$ sampai terjadi perubahan warna bening menjadi ungu kemerahan. Normalitas $\mathrm{KMnO}_{4}$ dihitung menggunakan persamaan 1 .

$\mathrm{N} \mathrm{KMnO}_{4}=\frac{(\mathrm{N} \cdot \mathrm{V}) \mathrm{H} 2 \mathrm{C} 2 \mathrm{O} 4}{\mathrm{a} \mathrm{mL} \mathrm{KMnO} 4}$

Sampel limbah laundry yang sudah dikoagulasi diambil sebanyak $1 \mathrm{~mL}$ kemudian diencerkan dengan aquades hingga volumenya menjadi $10 \mathrm{~mL}$ lalu dimasukkan kedalam Erlenmeyer dan tambahkan $5 \mathrm{~mL} \mathrm{H}_{2} \mathrm{SO}_{4}$ dan menambahkan larutan $\mathrm{KMnO}_{4}$ sesuai dengan volume hasil standarisasi $\mathrm{KMnO}_{4}$. Kemudian campuran larutan tersebut dipanaskan pada hot plate dengan sampai suhu suhu $\pm 80^{\circ} \mathrm{C}$ lalu ditambahkan larutan asam oksalat $10 \mathrm{~mL}$. Larutan kemudian dititrasi dengan larutan $\mathrm{KMnO}_{4}$ sampai berubah warna dari ungu kemerahan hingga ungu tua pekat (sebagai $\mathrm{b} \mathrm{mL}$ ). Analisis kadar COD dihitung menggunakan persamaan 2.

$$
\mathrm{COD}=\left[(\mathrm{a}+\mathrm{b}) \mathrm{mL} . \mathrm{N} \mathrm{KMnO} 4 \text { standarisasi }-(\mathrm{N} . \mathrm{V}) \mathrm{H}_{2} \mathrm{C}_{2} \mathrm{O}_{4}\right] \text {. (2) } 8000
$$




\subsubsection{Proses Penentuan Kadar Fosfat}

Penentuan kadar fosfat dilakukan dengan melakukan uji menggunakan metode uji SNI 6989.31-2005. Larutan induk fosfat disipakan dengan variasi konsentrasi $0,0 \mathrm{mg} / \mathrm{L}, 0,2 \mathrm{mg} / \mathrm{L}, 0,4$ $\mathrm{mg} / \mathrm{L}, 0,8 \mathrm{mg} / \mathrm{L}$, dan 1,0 mg/L.Pembuatan kompleks fosfat dilakukan dengan penambahan reagent ammonium molibdat. Penentuan fosfat pada sampel limbah laundry dilakukan dengan mengambil $50 \mathrm{~mL}$ sampel limbah dan dimasukkan kedalam Erlenmeyer lalu tambahkan 1 tetes indikator phenolphthalein jika larutan berubah warna menjadi merah muda maka larutan ditambahkan $\mathrm{H}_{2} \mathrm{SO}_{4}$ $5 \mathrm{~N}$ hingga warna merah muda hilang. Kemudian larutan ditambahkan $8 \mathrm{~mL}$ larutan campuran dan aduk hingga homogen. Perhitungan kadar fosfat mengacu pada metode standar SNI 6989.31-2005 dengan mengalikan kadar yang diperoleh dari pengukuran (C) dengan faktor pengencer (fp).

\section{HASIL PENELITIAN}

\subsection{Hasil Penentuan Kadar COD}

Penentuan kadar COD yang telah dilakukan dengan metode titrasi permanganometri, sehingga diperoleh kadar COD pada limbah laundry seperti yang ditampilkan pada Tabel 2.

TABEL II. Data hasil uji COD dengan koagulan kapur

\begin{tabular}{ccc}
\hline $\begin{array}{c}\text { Massa Koagulan } \\
\text { (gram) }\end{array}$ & $\begin{array}{c}\text { Kadar COD } \\
(\mathrm{mg} / \mathrm{L})\end{array}$ & $\begin{array}{c}\text { Efektivitas Penurunan } \\
(\%)\end{array}$ \\
\hline 0 & 1516 & - \\
1,8 & 926 & 38,89 \\
2,2 & 674 & 55,56 \\
2,8 & 463 & 69,44 \\
3,2 & 253 & 83,33 \\
3,5 & 168 & 88,89 \\
\hline
\end{tabular}

Berdasarkan hasil uji kadar COD pada Tabel 2, didapatkan hasil kadar COD dengan efektivitas penurunan 38,89\% sampai $88,89 \%$. Berdasarkan data hasil uji pada Tabel 2, dapat dibuat grafik hubungan antara massa koagulan dengan kadar COD, seperti yang ditunjukkan pada Gambar 1 .

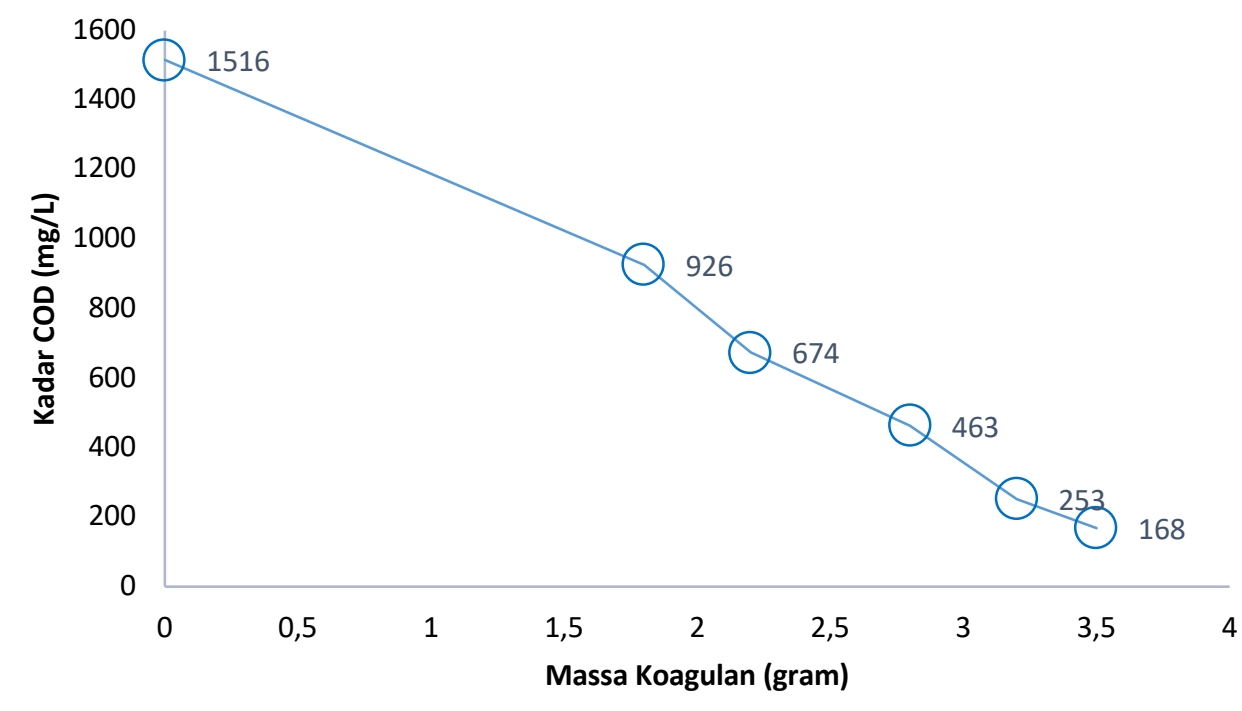

Gambar 1. Analisis Kadar COD yang terdapat didalam Sampel Limbah Laundry

Gambar 1. menunjukkan bahwa pada variasi massa koagulan kapur mempengaruhi nilai dari kadar COD. Efisiensi penurunan kadar COD tertinggi pada massa koagulan 3,5 gram yaitu $168 \mathrm{mg} / \mathrm{L}$ dengan efisiensi penurunan $88,89 \%$. Hasil tersebut sudah dapat memenuhi baku mutu lingkungan berdasarkan Perda Prov. Jateng No. 5 Tahun 2012. Dari penelitian ini penambahan koagulan mampu membantu kapur untuk mengikat partikel koloid yang terdapat pada limbah laundry sehingga 
terbentuk endapan yang memisahkan cairan dengan lumpur dari koagulan kapur. Ketika pertumbuhan flok dari massa dan skala ukurannya sudah maksimal flok-flok akan mengendap dan membentuk 2 lapisan yaitu lapisan jernih pada bagian atas dan endapan di bagian bawah gelas beker.

Menurut penelitian Zikri Rahimah, dkk (2016) dengan variasi dosis koagulan 1-5 g mampu menurunkan kadar COD hingga efisiensi 78,57\%. Sedangkan berdasarkan penelitian yang dilakukan oleh Maghfiroh Alifia Nugti dkk (2020) menggunakan koagulan CaO sebanyak 1,05 g dengan waktu pengadukan selama 30 menit dan kecepatan pengadukan $200 \mathrm{rpm}$ mampu menurunkan COD hingga efisiensi $71,43 \%$ dimana pada dosis tersebut kadar COD pada limbah laundry belum dapat memenuhi baku mutu [7]. Hal ini menunjukkan semakin tinggi massa dari koagulan kapur yang ditambahkan kedalam sampel limbah laundry maka akan semakin tinggi pengikatan antar flok dan semakin banyak partikel koloid yang akan menggumpal dan mengendapkan zat-zat organik yang terdapat pada limbah laundry dan kadar COD pada limbah akan semakin berkurang.

\subsection{Hasil Penentuan Kadar Fosfat}

Penentuan kadar fosfat yang telah dilakukan dengan metode uji SNI 6989.31-2005, sehingga diperoleh kadar fosfat pada limbah laundry seperti yang ditampilkan pada Tabel 3.

TABEL III. Data hasil uji Fosfat dengan koagulan kapur

\begin{tabular}{ccc}
\hline $\begin{array}{c}\text { Massa Koagulan } \\
(\text { gram })\end{array}$ & $\begin{array}{c}\text { Kadar Fosfat } \\
(\mathrm{mg} / \mathrm{L})\end{array}$ & $\begin{array}{c}\text { Efektivitas Penurunan } \\
(\%)\end{array}$ \\
\hline 0 & 6,115 & - \\
1,8 & 0,021 & 99,66 \\
2,2 & 0,013 & 99,79 \\
2,8 & 0,003 & 99,95 \\
3,2 & 0,002 & 99,97 \\
3,5 & 0,001 & 99,98 \\
\hline
\end{tabular}

Berdasarkan hasil uji kadar fosfat pada Tabel 3, didapatkan hasil kadar fosfat dengan efektivitas penurunan $38,89 \%$ sampai $88,89 \%$. Berdasarkan data hasil uji pada Tabel 3, dapat dibuat grafik hubungan antara massa koagulan dengan kadar fosfat, seperti yang ditunjukkan pada Gambar 2.

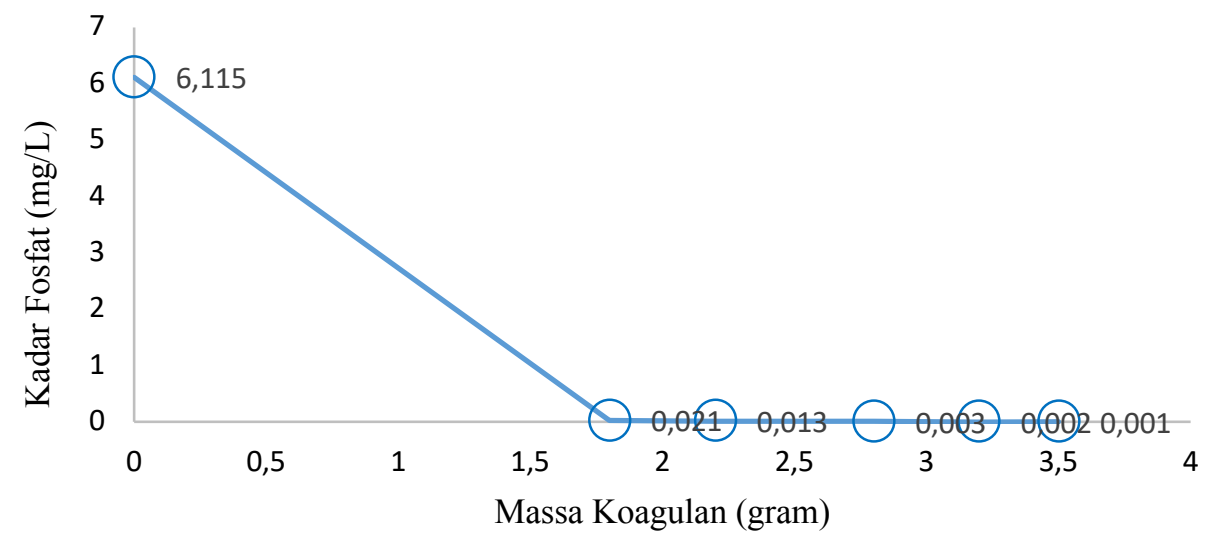

Gambar 3. Analisis Kadar Fosfat yang terdapat didalam Sampel Limbah Laundry

Gambar 3 menunjukkan bahwa pada variasi massa koagulan kapur mempengaruhi nilai dari kadar fosfat dimana semakin banyak massa koagulan kapur yang ditambahkan pada sampel limbah laundry maka akan semakin tinggi efisiensi penurunan fosfat. Efisiensi penurunan kadar fosfat tertinggi pada massa koagulan 3,5 g yaitu $0,001 \mathrm{mg} / \mathrm{L}$ dengan efisiensi penurunan $99,98 \%$, akan tetapi pada massa koagulan kapur 1,8 g sudah mampu menurunkan kadar fosfat $0,021 \mathrm{mg} / \mathrm{L}$ hal ini sudah dapat memenuhi baku mutu lingkungan berdasarkan Perda Prov. Jateng No. 5 Tahun 2012.

Koagulan kapur efektif dalam menurunkan kadar fosfat karena menurut Zikri Rahimah, dkk (2016) senyawa penyusun zat kapur akan bereaksi dengan orthophorus membentuk endapan 
hydrocyaptite, dimana fosfor dan polyphosphate akan dipisahkan dengan reaksi adsorpsi dan akan membentuk endapan [1]. Adanya perbedaan efisiensi penurunan setiap kadar COD dan fosfat dapat dipengaruhi oleh lamanya waktu pengadukan, karena semakin lama waktu pengadukan maka semakin banyak endapan dihasilkan sehingga nilai efisiensi semakin tinggi, akan tetapi pada penelitian ini lamanya waktu pengadukan tidak mempengaruhi penurunan kadar fosfat secara signifikan. Selain itu, lama waktu pengendapan dimana semakin lama waktu untuk pengendapan sampel maka cairan yang terpisahkan dari flok akan semakin banyak sehingga proses pengendapan terjadi dengan sempurna dan air akan semakin jernih. Menurut Tambak Manurung, dkk (2012) kecepatan pengadukan dapat berpengaruh terhadap proses pembentukan flok, jika kecepatan pengadukan lambat ikatan flok akan lemah dan flok yang dihasilkan akan sedikit, dan apabila kecepatan pengadukan terlalu cepat flok yang terbentuk dapat terurai kembali karena tumbukan antar partikel menimbulkan gaya gesek yang tinggi dan susunan flok tidak sesuai yang diharapkan sehingga diperlukan pengadukan yang stabil [8].

\section{KESIMPULAN}

Berdasarkan penelitian ini dapat disimpulkan bahwa adanya pengaruh setelah penambahan koagulan kapur pada sampel limbah laundry sehingga mampu menurunkan kadar COD sebelum treatment koagulasi $1516 \mathrm{mg} / \mathrm{L}$ mengalami penurunan tertinggi pada massa koagulan kapur sebesar 3,5 g dengan kadar COD $168 \mathrm{mg} / \mathrm{L}$ dan efisiensi 88,89\%. Pada penurunan kadar fosfat sebelum treatment koagulasi sebesar $6,115 \mathrm{mg} / \mathrm{L}$ mengalami penurunan tertinggi pada massa koagulan kapur sebesar 3,5 g dengan kadar fosfat 0,001 mg/L dan efisiensi 99,98\% sehingga dari uji kadar COD dan fosfat tersebut sudah mampu memenuhi baku mutu lingkungan.

\section{Daftar Pustaka}

[1] Z. Rahimah, H. Heldawati, and I. Syauqiah, "Pengolahan limbah deterjen dengan metode koagulasi flokulasi menggunakan koagulan kapur dan pac," Konversi, vol. 5, no. 2, pp. 13-19, 2016.

[2] B. H. Prabowo, H. Hendriyana, L. Nurdini, M. C. Firdaus, and T. Leinaldy P., "Metode Koagulasi Dan Elektrokoagulasi Dengan Penambahan Hidrogen Peroksida Pada Proses Pengolahan Limbah Cair Buangan Laundry," Eksergi, vol. 16, no. 2, p. 53, 2019, doi: 10.31315/e.v16i2.2812.

[3] S. W. Astuti and M. S. Sinaga, "Pengolahan Limbah Laundry Menggunakan Metode Biosand Filter Untuk Mendegradai Fosfat,” J. Tek. Kim. USU, vol. 4, no. 2, 2015.

[4] Rahmawati, Chadijah, and A. Ilyas, "Analisa Penurunan Kadar COD Dan BOD Limbah Cair Laboratorium Biokimia Uin Makassar Menggunakan Fly Ash (Abu Terbang) Batubara,” Al-Kimia, pp. 64-75, 2013.

[5] B. Murwanto, "Efektivitas Jenis Koagulan Poly Aluminium Chloride Menurut Variansi Dosis dan Waktu Pengadukan terhadap Penurunan Parameter Limbah Cair Industri Tahu," J. Kesehat., vol. 9, no. 1, p. 143, 2018, doi: 10.26630/jk.v9i1.771.

[6] W. T. D. Astuti, T. Joko, and N. A. Y. Dewanti, "EFEKTIVITAS LARUTAN KAPUR DALAM MENURUNKAN," J. Kesehat. Masy., vol. 4, no. 3, pp. 941-948, 2016.

[7] M. A. Nugti, S. Mei, D. Cahyani, L. Latifah, and A. Sugiharto, "Uji Efektifitas Koagulan Kapur ( CaO ), Ferri Klorida ( $\mathrm{FeCl} 3$ ), Tawas ( $\mathrm{Al} 2(\mathrm{SO} 4) 3$ ) Terhadap Penurunan Kadar PO4 dan COD Pada Limbah Cair Domestik ( Laundry ) Dengan Metode Koagulasi,” vol. 2, pp. 345-348, 2020.

[8] T. Manurung, Y. Dewi, and B. Lekatompessy, "Efektivitas Biji Kelor (Moringa Oleifera) pada Pengolahan Air Sumur Tercemar Limbah Domestik," J. Ilm. Fak. Tek. LIMIT'S, vol. 8, no. 1, pp. 37 46, 2012.

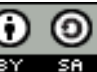

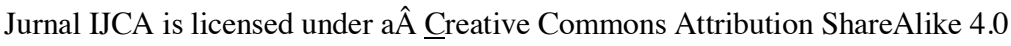

